\title{
Entre o músico e o professor: o percurso do reconhecimento
}

\section{Between the musician and the teacher: the path of recognition}

Anderson Brasil ${ }^{1}$ Universidade Federal do Recôncavo da Bahia - UFRB sonsbrasil@ufrb.edu.br

Ana Paula Caetano ${ }^{2}$ UIDEF, Instituto de Educação, Universidade de Lisboa apcaetano@ie.ulisboa.pt

Ana Paz ${ }^{3}$

UIDEF, Instituto de Educação, Universidade de Lisboa apaz@ie.ulisboa.pt 


\section{Resumo}

Este artigo se antepara em uma pesquisa de abordagem qualitativa que teve como sujeitos sociais músicos portugueses e brasileiros que se tornaram docentes. O trabalho assume como objetivo discutir o percurso e os processos pelos quais construíram o reconhecimento de si como professores de música, a partir de entrevistas narrativas, e refletir sobre as potencialidades desta estratégia de contar histórias da sua história de vida na investigação na área da educação musical. Os resultados interpretados alcançam um conjunto complexo de momentos e acontecimentos, desenhando caminhos para alguns inesperados e não desejados, que no conjunto vão proporcionando experiências nas quais percebem o sentido de ser na relação com o outro e nas quais constroem os saberes que mobilizam no seu cotidiano profissional, permitindo que o "saber docente" escape a exclusividade da formação acadêmica, sendo construído também por meio do constante deslocamento do passado e do futuro destes sujeitos sociais.

Palavras-chave: Profissionalização docente em música. Narrativas de profissionalização. Histórias de vida. Reconhecimento profissional.

\section{Abstract}

This article is a preliminary to a qualitative approach research that had Portuguese and Brazilian musicians as social subjects who became teachers. The work aims to discuss the path and processes by which they built their recognition as music teachers, based on narrative interviews and reflect on the potentialities of this strategy of telling stories of their life history in the investigation in the area of Music Education. The results, interpreted, reach a complex set of moments and events, drawing paths for some unexpected and unwanted, which as a whole provide experiences in which they perceive the sense of being in the relationship with the other. and in which they build the knowledge that they mobilize in their professional daily lives, allowing the "teaching knowledge" to escape the exclusivity of academic education, being also built through the constant displacement of the past and future of these social subjects.

Keywords: Professionalization teacher in music. Narratives of professionalization. Life stories. Professional acknowledgment.

\footnotetext{
1 Pós-doutorado em Educação pela Universidade de Lisboa (ULisboa). Doutorado em Música pela Universidade Federal da Bahia, Mestrado e Graduação em Música pela mesma instituição. Professor adjunto na Universidade Federal do Recôncavo da Bahia. 2 Doutorado em Ciências da Educação, Mestrado em Ciências da Educação - Psicologia da Educação. Professora Associada do Instituto de Educação da Universidade de Lisboa.

3 Doutorado em Educação pela Universidade de Lisboa. Mestrado em Sociologia pela Universidade Nova de Lisboa. Professora Auxiliar no Instituto de Educação da Universidade de Lisboa. Investigadora na UIDEF - Unidade de Investigação da Universidade de Lisboa.
} 


\title{
Primeiras pinceladas...
}

Este estudo 4 busca discutir o percurso do reconhecimento de alguns professores de música a partir das narrativas de díspares docentes que atuam em distintos âmbitos educacionais em Portugal e no Brasil. A discussão acerca da profissão de professor de música demanda uma compreensão basilar da multiplicidade do saber pedagógico-musical. A educadora musical Cláudia Bellochio defende mesmo que "não há uma concepção única para a formação do professor de educação musical" (BELLOCHIO, 2003, p.23). Neste sentido, o exercício profissional da docência pleiteia considerar tanto os aspectos epistemológicos que envolvem as concepções da formação docente como as dimensões curriculares e os espaços de atuação profissional do professor.

A pesquisa que aqui se apresenta não se destina a delinear ou defender um perfil específico para o professor que atua no ensino da música ou em diferentes formas, contextos e situações de ensino; antes, tem como problema central a compreensão dos percursos de (auto)reconhecimento deste "professor de música" que, antes de ser professor ou que além de ser professor, é também músico. Procura problematizar como ambas as dimensões identitárias se relacionam, conflituam, convergem, integram e se, ou como, as experiências em cada uma das esferas de atuação implicam a apropriação de construção de saberes em uso na outra. Kraemer $(2000$, p.51) fornece um primeiro mote quando defende que a educação musical tem como objeto "as relações entre a(s) pessoa(s) e a(s) música(s) sob os aspectos de apropriação e transmissão".

Ao discutir o caminho do professor na área de educação musical, adentraremos em diferentes entretons sobre os saberes necessários à docência de música, características do campo de conhecimento apontadas em realidades onde acontecem o ensino e a aprendizagem de música nos dois países focalizados. Chagas Neto (2018), ao buscar compreender as causas que conduzem um instrumentista a atuar na docência, nos auxilia ao ponderar outros questionamentos:

\begin{abstract}
A oportunidade de trabalhar em uma instituição de ensino, adquirir um vínculo empregatício e obter um plano de carreira são atrativos relevantes para essa escolha. Isto nos faz refletir sobre a relação músico/professor, que traz algumas inquietações científicas para tentar compreender a causa de um instrumentista em atuar na docência, já que, como visto, não faz parte dos seus objetivos iniciais. Como, no decorrer de sua vida, um músico instrumentista adere como profissão o ato de ensinar? Quais são os aspectos motivacionais para isso? Esses profissionais se reconheceram como tal? (CHAGAS NETO, 2018, p.16).
\end{abstract}

Diante dos aspectos acima descritos, estabelecemos como objetivo específico perceber de que maneira se dá o percurso até que o músico se "torne" professor de música. O cenário descrito por Brasil (2019) é tomado por centelha nesta nova pesquisa, quando descreve a paisagem que perpassa como papel de fundo na profissionalização de muitos músicos brasileiros.

4 Este artigo resulta de uma pesquisa de pós-doutoramento realizada na Universidade de Lisboa. Foi financiada pela Fundação para a Ciência e a Tecnologia (FCT), no âmbito da Unidade de Investigação e Desenvolvimento em Educação e Formação (UIDEF, UIDB/04107/2020). 
A experiência não depende apenas das condições externas e objetivas, mas é determinada pelo desejo, pela coerência interna entre suas convicções, atitude e propósito de cada um, mesmo em se tratando de um cenário marcado pela sobrevivência em meio à carência de recursos, à violência e discriminação. (BRA-

SIL, 2019, p.172).

O autor descreve uma dinâmica sobremodo peculiar na formação profissional do músico brasileiro, a qual difere da construção social que legitima outras profissões:

Se formaram dentro da própria profissão de músico. O contexto que oportunizou vivências práticas com diferentes experiências musicais os induziu a um conhecimento angariado na prática, com diferentes fontes de aprendizagem. Eles declaram que, quando perceberam, já estavam na TV, tocando ao lado de seus ídolos, não houve anúncio dizendo: "Olha, se liga, você já é um músico profissional!". (BRASIL, 2019, p.172).

A partir dessa descrição de uma formação que acontece na própria "ação", por meio de diferentes fontes de aprendizagem, somos impelidos a realizar uma outra inquietante pergunta: quando percebemos que somos "professores de música"? Será que é no dia que recebemos o diploma? É possível conceber um momento em comum para esta descoberta em meio aos dados empíricos desta pesquisa? Para ampliarmos estas reflexões e trazermos luz para outras demandas, adentramos em diálogo com alguns teóricos que abordam a temática em questão.

\section{Caminhos do reconhecimento}

Quando acontece esse "reconhecimento" de ser professor? O filósofo francês Paul Ricoeur situa inicialmente que o reconhecimento de si se dá por outra pessoa que não a si mesmo, isto é, a identidade de si constrói-se na alteridade pela qual o outro - um outro corpo, com uma outra história, portador de direitos no contexto das instituições e da sociedade - é "interlocutor no plano do discurso e protagonista ou antagonista no plano da interação" (RICOEUR, 1997, p.129). O reconhecimento é, desse modo, um percurso que envolve uma noção epistemológica acerca da identificação, perpassando o reconhecimento como uma habilidade antropológica de aceitar a si, tendo, por fim, o reconhecimento em sua dimensão ética e política de viver com o outro em instituições justas (RICOEUR, 1997, 2006). Também a gratidão permeia a construção teórica do filósofo francês. Ricoeur desenvolve a ideia de que a gratidão proporciona a retribuição do reconhecimento, ou seja, devolvemos para o outro, reconhecendo-o.

Neste caminho se alcança a alteridade, o respeito, a igualdade (RICOEUR, 2007). Estes valores serão a força motriz para a construção de um "estado de paz" que, por ele, possuirá passagem para a troca de reconhecimentos como virtude, uma dimensão em que a troca não acarreta compromisso. A doação não gera uma obrigação, o reconhecimento legítimo não exige nada de volta, é recíproco, é a troca em sua forma autêntica, pura. $\mathrm{O}$ autor alicerça o reconhecimento sobre três pilares fundamentais: "o reconheci- 
mento mútuo, o reconhecimento como identidade e o reconhecimento de si mesmo" (RICOEUR, 2006, p.74). Essa construção do reconhecimento embebido pela alteridade permite assentar de forma indubitável a prática educacional ao propósito da dádiva, da doação. Mas como se constrói esta relação de reconhecimento do outro? Quando aprendemos a escutar a nós mesmos, ao refletirmos e ao nos narrarmos.

A narratividade é um elo e interseção de histórias e ficção, onde acontece "a sobreposição do passado, enquanto o espaço da memória, e da história do futuro, enquanto o espaço da expetativa e da esperança, e do presente, enquanto o momento da atenção e da inciativa" (RICOEUR, 1997, p.116). Narrar é uma prática indissociável de ouvir-se. Ouvimo-nos ao narrarmos. Mas "narrar é também um ato discursivo que aponta para fora de nós mesmos, em direção a uma reelaboração do campo prático de quem recebe" (RICOEUR, 1997, p.115). Para Ricoeur (2006), o reconhecimento de si não pode acontecer sem o outro; indo um pouco além, ele nos leva a sermos nós quando somos o outro, sendo o outro estando em si mesmo. O reconhecimento para acontecer carecerá estar para além da alteridade, envolverá o amor-próprio, a humildade, um aprender a se amar (RICOEUR, 2006). O amor-próprio, a compreensão acerca da nossa própria existência e ao que nós percebemos e vivemos acabam por tecer a própria existência. Saldanha (2009, p.360) sustenta o reconhecimento como força motriz nessa construção sobre a existência:

O reconhecimento de si possibilita uma sabedoria prática, na qual o homem que se conhece pode recorrer a qualquer momento, fazendo-se capaz. A existência de um homem capaz não pressupõe, porém, a existência de um homem incapaz, mas, sim, a existência de quem é capaz e para que ele é capaz. Percebe-se, ainda, que o homem afirma-se e atesta-se como sujeito corpóreo, de carne e osso, capaz de se designar, de agir, de narrar a história da sua vida e de se apresentar e assumir como autor responsável pelos seus atos.

Desta forma, é possível alcançar que o reconhecimento não é baseado no presente, é um entrecruzamento que perpassa passado e futuro, onde se pincela o que passou, lançando expectativas sobre o vindouro, onde um dos pilares é a própria história de vida.

Na verdade, fundado tanto numa história de vida, como em compromissos e expectativas futuras, tal reconhecimento proporciona-nos uma imagem do si mesmo na sua distensão temporal para o passado (Memória) e para o futuro (a promessa), mas enraizado num presente entendido como presença e como iniciativa. (SALDANHA, 2009, p. 162).

Assim, o aprendizado também se institui a partir do autoconhecimento, do narrar-se. Ricoeur (2006, p.115) nos ensina que desenvolver a narrativa auxilia o nosso processo de formação: "Aprender a 'narrar-se' poderia ser o benefício da apropriação da autocrítica. Aprender a narrar-se é também aprender a narrar a si mesmo de outro modo". A narrativa e a alteridade, para o filósofo, permeiam o próprio conhecimento de si mesmo, aprendendo por meio da humildade a desenvolver o amor-próprio.

Este desenvolvimento de amor-próprio por meio do autoconhecimento é uma via 
de mão dupla, pois, ao nos conhecermos, somos por vezes compelidos a "enxergar" o outro. Ao enxergamos o outro, transferimos demandas oportunizadas pelo amor e, em meio a toda a transferência, é possível trazer demandas de amor (HARARI, 1990).

Este percurso do reconhecimento esquadrinhado até aqui compreende uma clara necessidade de reconhecer o outro e de reconhecer-se como o condutor, escritor de sua própria história. Mas qual é esta história? O que trata esta biografia? É um conto pautado na experiência, na vida. Estas biografias com seus assinalados acontecimentos entrelaçam experiências que tecem os fios da formação docente, como defendem Burnier et al. (2007, p.348):

\footnotetext{
Esses elementos da subjetividade docente, por sua vez, estão marcados pelas experiências vividas pelos indivíduos ao longo de suas vidas, pelos discursos, pelas instituições e grupos aos quais tiveram acesso, participantes também da construção dos significados que esses docentes irão conferir às suas experiências em geral e à docência em particular.
}

Em virtude disto, a docência é percebida aqui como um conjunto complexo de trocas entre diferentes momentos e diferentes acontecimentos, permitindo que o saber docente escape à exclusividade específica da formação acadêmica, sendo construído por meio do constante deslocamento do passado e do futuro, ou, nas palavras de Latour (2000, p.357): "Trazer as coisas de volta, para que outras possam ser enviadas e se tornarem, assim, familiarizadas com as coisas e pessoas".

\section{Abordagem narrativa: tecendo os fios da pesquisa}

A escolha por este design de pesquisa justifica-se por se tratar de um formato robusto para alcançar aspectos dimensionais, não só das ações, mas das diversas imbricações presentes na formação docente, como nos esclarece André (1997). As entrevistas narrativas são percebidas aqui como uma porta capaz de alcançar memórias, valores construídos, projetos, "identidades do em si-mesmamento" (RICOEUR, 1997, p.128). Compreendemos que por meio delas também conseguimos nos embrenhar por distintos universos socioculturais, transitando entre as dimensões pessoal e profissional, sendo a nossa bússola metodológica neste percurso Dominicé (1988), Nóvoa (1992) e Josso (1999).

Neste caminho, como nos estimula Abreu (2011), acreditamos que as narrativas podem auxiliar na apreensão acerca das motivações que conduziram os músicos entrevistados a atuar na docência:

O método narrativo não tem a intenção de reconstruir a história de vida dos professores, mas, sim, compreender os contextos em que essas biografias foram construídas e os fatores que produzem mudanças e motivam as ações dos professores. Esse método possibilita conhecer não só o professor, mas a relação deste com o contexto educacional em que está inserido, identificando, dessa maneira, o seu processo de profissionalização docente. (ABREU, 2011, p.157). 
A imersão nos contextos biográficos dos docentes entrevistados nos permite não só uma compreensão acerca do "vir a ser professor", mas ainda, tal como esclarece o pedagogo António Nóvoa, possibilita adentrar em outras formas de "ser" e de "estar" na docência que:

Se apropria do sentido da sua história pessoal e profissional", sendo a identidade, não um dado adquirido, uma propriedade ou um produto, mas "um lugar de lutas e conflitos" e um "espaço de construção de maneiras de ser e de estar na profissão. (NÓVOA, 2000, p.16).

Desta maneira, por meio da revisitação e da narração, alcançando a subjetividade, as minúcias e singularidades de cada narrativa, é possibilitado um organismo participativo entre os pesquisadores e os professores entrevistados, pela elaboração de uma hermenêutica interpretativa das suas falas. Connelly e Clandinin (1990) nos amparam na reflexão de que o ser humano é por natureza um contador de histórias e de que o processo educativo é um processo narrativo em que somos interlocutores, construindo histórias conjuntas a partir das histórias que personificamos e contamos uns aos outros.

\begin{abstract}
A razão principal da utilização da narrativa na investigação educacional reside no fato de o homem ser um potencial contador de histórias que, individual ou socialmente, vivencia uma história de vida. O estudo da narrativa é, por assim dizer, o estudo do modo como o ser humano "sente" o mundo. Esta noção geral traduz a opinião de que a educação é a construção e a reconstrução de histórias pessoais e sociais: professores e alunos são os contadores de histórias e as personagens das suas próprias histórias e das histórias dos outros. (CONNELLY; CLANDININ, 1990, p.2).
\end{abstract}

Josso (2010), por sua vez, nos esclarece que histórias de vida são capazes de amplificar detalhes esmiuçadores da vida social, podendo alcançar feitos como pertencimento e existencialidade, isto por meio da ponderação do vivido, pela interpretação do narrar-se. As autobiografias ganham protagonismo nesta trama metodológica, em virtude de trazer um conjunto de rupturas e imprevisibilidades na tessitura da teia da vida, tornando-se pedra angular na percepção do trajeto descrito pelos docentes convidados, como Passeggi $(2011$, p.154) nos ajuda a compreender: "Do ponto de vista psicológico da construção da subjetividade, as escritas autobiográficas mostram justamente à pessoa que narra essa descontinuidade, as rupturas, a imprevisibilidade, o fortuito e o papel das contingências".

A autora segue nos transportando por este norte epistemológico quando nos origina a relação direta entre os estudos de narrativa e a evolução dos contextos profissionais que circundam a docência: "permite ter a medida das mutações sociais e culturais nas vidas singulares e relacioná-las com a evolução dos contextos de vida profissional e social" (PASSEGGl, 2008, p.25). 


\section{Indicações do caminho}

A partir de leituras embebidas em narrativas e histórias de vida, começamos a esquadrinhar maneiras de conduzir as entrevistas. $O$ conjunto de teóricos escolhidos aponta uma direção para o procedimento metodológico, com as indicações que a abordagem narrativa demanda, de forma inegociável, e que traçam as condições peculiares sobre a recolha dos dados, bem como para a gestação do roteiro de entrevista e para a meticulosidade da análise dos fenômenos.

Este desenho de pesquisa nos permitiu produzir 19 questões norteadoras, as quais estavam distribuídas em três distintos blocos:

\section{Roteiro de entrevista}

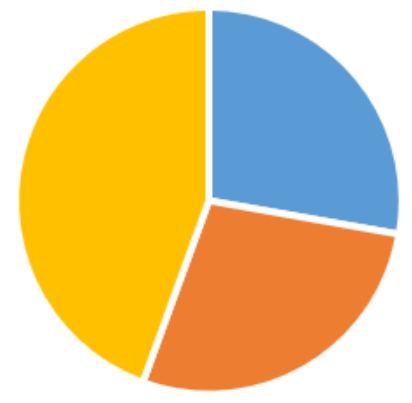

- SOCIAL

- ACADÊMICO / SABERES EXPERIENCIAIS

- ESCOLHA DA PROFISSÃO

Gráfico 1: Roteiro da entrevista. Fonte: Elaboração própria (2020).

A condução da entrevista seguiu o modelo proposto por Jovchelovitch e Bauer (2002), onde se propõe que a exploração do campo, em diálogo com a literatura específica sobre o problema da pesquisa, permita conceber um tópico inicial para narração e para situar o participante. Diante desta orientação, foi aplicado um "teste-ensaio" da entrevista, buscando averiguar a funcionalidade e a clareza das questões escolhidas. Os participantes foram informados no início da pesquisa acerca do contexto do estudo e de que maneira seria procedida a entrevista narrativa. Seguindo as indicações dos autores, as entrevistas realizaram-se sem interrupção. 


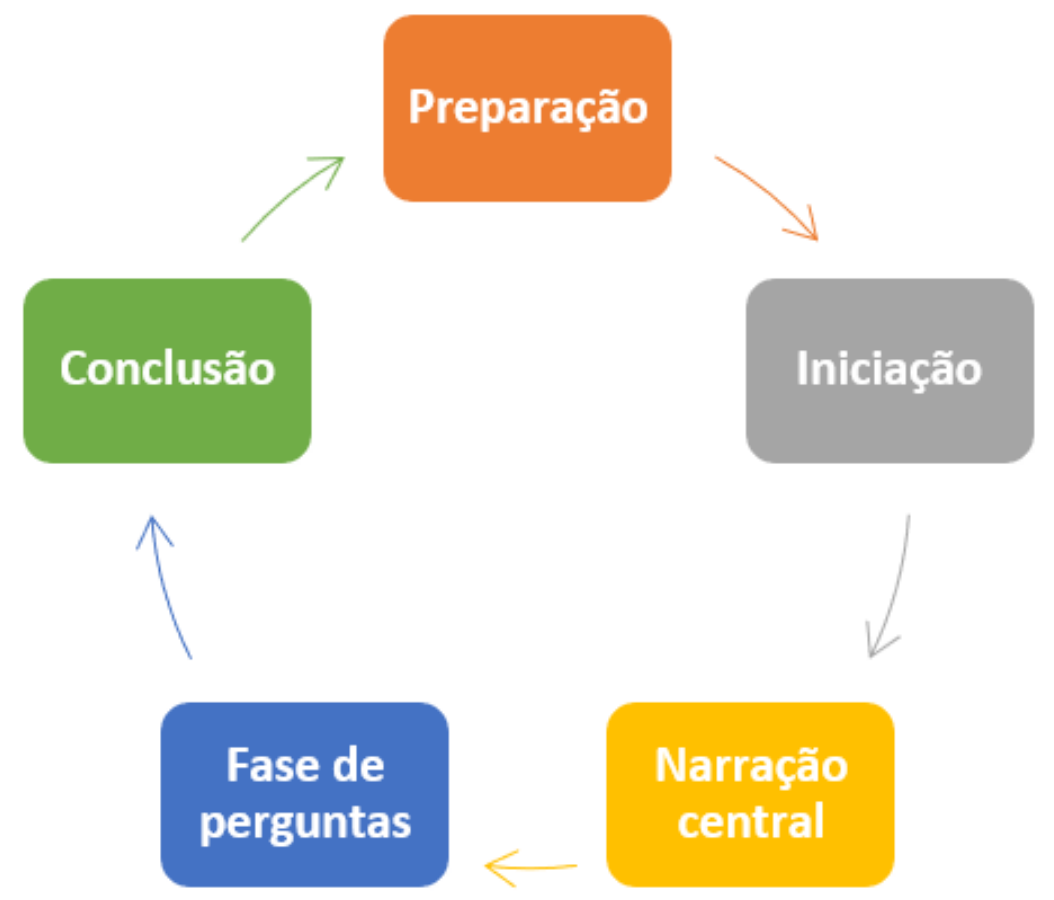

Imagem 1: Etapas de realização das entrevistas. Fonte: Elaboração própria (2020).

\section{Participantes da pesquisa}

Após delineado o problema, o caminho metodológico e o campo empírico de pesquisa, foi realizado o convite aos professores. Para tanto, tomou-se como condição sine qua non que os docentes convidados possuíssem um currículo pregresso como instrumentistas e que ocupassem diferentes âmbitos educacionais do ensino de música, tanto em Portugal como no Brasil.

Os pesquisadores realizaram avaliações meticulosas acerca de cada perfil para que as variáveis existentes entre contextos culturais e geográficos fossem equacionadas com o entrecruzamento de tempo na docência. ${ }^{5}$

Vencidas as etapas sugeridas por Jovchelovitch e Bauer (2002) e Amado (2014), foram convidados a participar desta pesquisa quatro professores brasileiros e quatro professores portugueses. Todos os docentes possuíam mais de 15 anos de atuação na docência e lecionavam música em distintos âmbitos educacionais. Desta maneira, os participantes foram identificados apenas pelas letras iniciais de seus nomes, formação, nacionalidade e atuação profissional, conforme apresentamos no quadro a seguir.

5 Foram convidados a participar do estudo músicos com destacadas biografias musicais e que possuíam mais de 15 anos na docência. 


\begin{tabular}{|c|c|c|}
\hline NOME E NACIONALIDADE & FORMAÇÃO & ATUAÇÃO \\
\hline F.A. - Português / Argentino & Bacharel e mestre em Música & $\begin{array}{l}\text { - Ensino particular de piano e } \\
\text { teoria musical } \\
\text { - Instrumentista } \\
\text { - Acompanhador } \\
\text { - Arranjador } \\
\text { - Compositor } \\
\text { - Maestro }\end{array}$ \\
\hline I.F. - Português & Licenciado em Música & $\begin{array}{l}\text { - Projeto Social em Música } \\
\text { - Instrumentista } \\
\text { - Maestro }\end{array}$ \\
\hline V.F. - Português & $\begin{array}{l}\text { Doutorando em Artes / Bacharel } \\
\text { em Música }\end{array}$ & $\begin{array}{l}\text { - Ensino Superior da Música } \\
\text { - Ensino de performance de } \\
\text { trombone } \\
\text { - Músico em orquestra }\end{array}$ \\
\hline J.N. - Português & $\begin{array}{l}\text { Psicólogo / Mestre e doutor em } \\
\text { Ciências da Educação }\end{array}$ & $\begin{array}{l}\text { - Ensino Superior da Música } \\
\text { - Coordenação de Pós-Gradua- } \\
\text { ção em Música } \\
\text { - Instrumentista }\end{array}$ \\
\hline V.S. - Brasileiro & $\begin{array}{l}\text { Mestre e Licenciado em Música } \\
\text { / Doutorando em Música }\end{array}$ & $\begin{array}{l}\text { - Ensino fundamental / música } \\
\text { - Instrumentista } \\
\text { - Acompanhador } \\
\text { - Arranjador }\end{array}$ \\
\hline L.S. - Brasileiro & $\begin{array}{l}\text { Licenciado, mestre em doutor } \\
\text { Música }\end{array}$ & $\begin{array}{l}\text { - Ensino Superior da Música } \\
\text { - Instrumentista }\end{array}$ \\
\hline D.X. - Brasileiro & Licenciando em Música & $\begin{array}{l}\text { - Ensino em Projetos Sociais em } \\
\text { Música } \\
\text { - Ensino particular de percussão } \\
\text { e teoria musical } \\
\text { - Instrumentista }\end{array}$ \\
\hline F.S. - Brasileiro & Licenciado em Música & $\begin{array}{l}\text { - Ensino particular de violão e } \\
\text { teoria musical } \\
\text { - Compositor } \\
\text { - Cantor } \\
\text { - Instrumentista }\end{array}$ \\
\hline
\end{tabular}

Quadro 1: Identificação dos professores entrevistados (Portugal e Brasil). Fonte: Elaboração própria (2020). 


\section{Realização e procedimentos de análise das entrevistas}

As entrevistas foram realizadas separadamente com cada convidado. O tempo de duração de cada uma delas oscilou entre 48 e 124 minutos de duração. Tivemos cuidado não só na captação das palavras, mas também na consciência de que a transcrição é o momento de um novo passo no processamento da pesquisa (AMADO, 2014).

Seguindo as orientações de João Amado (2014), as entrevistas foram transcritas integralmente pelo próprio entrevistador para evitar divergências entre as falas capturadas na gravação e os dados transcritos. O autor alerta para a necessidade de revisitar os envolvimentos e emoções no momento da transcrição, com vistas a impetrar a profundidade do constituído, capturando o que o entrevistado quis apresentar em suas falas pregressas. A transcrição contendo todas as falas dos entrevistados de ambos os países resultou num total de 56 páginas.

Após a transcrição, iniciamos um procedimento de leitura ordenada de cada uma das entrevistas em busca dos elementos que pudessem se relacionar ao objeto de pesquisa. Esta relação com os trechos escolhidos se deu pelo seguinte direcionamento:

A análise das narrativas poderá encaminhar-se para perspectivas que salientem os conteúdos ou a forma, ou que tenham em conta o seu caráter holístico (o texto e a história de vida como um todo, interpretando-se cada parte em confronto com as restantes), ou as categorias temáticas (temas e categorias de uma análise de conteúdo). A análise de conteúdo permite o confronto e comparação de várias narrativas, ao passo que a análise holística é mais pertinente quando nos debruçamos sobre um relato apenas e intencionalmente tomado em profundidade. (AMADO, 2014, p.177).

No último procedimento, catalogamos os fragmentos para introdução neste estudo, concretizando a identificação de cada fala pelas letras que abreviam nome e sobrenome do entrevistado, campo educacional no qual atuava e o país de cada um dos docentes e, por último, a data de realização da entrevista.

\section{Para mim não existia o desejo de ser professor...}

A música se apresenta como força motriz na fala destes professores que perscrutam lugares quase inalcançáveis, em grande parte olvidados, tais como os da sua infância. A descoberta a respeito da profissionalidade acontece muitas vezes de forma totalmente inesperada, improvável, parecendo que o único sentido é o da sobrevivência, como nos ilustra o professor F.S.:

Virar professor... aconteceu, cara. Quando você olha, você está acordando cinco e meia da manhã para ir para a escola. Você está na sala de aula da universidade cursando licenciatura, mas ainda segue se perguntando "como foi que eu vim parar aqui?". Seus colegas perguntam: "Está fazendo o que da vida?". E, quando você responde que virou professor, é aquele espanto enorme... porque era totalmente improvável que isso fosse acontecer. O que eu pensava em ser? Até hoje 
eu não sei. Eu sei que eu pensaria em tudo, meu amigo, menos... ser professor [risos]. Só que a coisa foi acontecendo. Você gosta muito de tocar, de ser músi$c o$, de viver tocando. Mas a realidade é cruel, não tem como você viver só como músico, aí você aceita que a única saída é dar aula. (F.S., 2019).

O professor complementa e reforça a sua fala e, no que diz, se percebe a importância do outro e do respeito na relação, quando o outro é interlocutor e protagonista, mas também quando é antagonista.

O que me fez ser professor? A necessidade. Mas antes de me formar eu já estava dando aula em três lugares, três conservatórios. Um deles inclusive trabalhava com crianças autistas, o que me deu essa calma de escutar, de trabalhar o outro e entender o tempo do outro; isso eu consegui nesse lugar. $E$ aí eu fui trabalhar na escola particular. $O$ dinheiro era muito pouco, as exigências eram gigantescas, e a falta de respeito também. O que me levou a dar aulas particulares? Foi... sabe quando você toma uma pancada na cabeça e perde o rumo? (F.S., 2019).

Este encontro com o ensino de forma despropositada independe do âmbito educacional, bem como o contexto sociocultural, como podemos perceber na exposição do músico português V.F.:

Mas a docência, no meu caso, não foi um projeto. Eu gosto muito de ensinar, de estar com os alunos. Mas tenho um problema, os alunos, eles próprios poderiam fazer mais. Como, na minha formação, eu poderia ter feito mais? Podia, mas eu, a partir dos 13,14 anos, eu mesmo precisava comprar minhas partituras, meus CDs. Mal acabei o ensino profissional e comecei logo a dar aula. Sendo que logo aos 21 eu ganhei lugar na orquestra e aí deixei de dar aula por uns tempos, e aí voltei a dar aula a convite lá da Universidade do Minho, que ainda estou lá. (V.F., 2019).

O professor V.F., além de docente em uma universidade portuguesa, é também músico em uma orquestra profissional, lançando-nos na dimensão da precocidade com que estes músicos iniciam as suas experiências como "professores". O professor L.S., que atua em uma universidade brasileira, nos diz o seguinte sobre esta precocidade: "Eu comecei a dar aula [quando] eu tinha 14 anos, comecei a dar aula de violão. Hoje eu estou com 29 anos, então tem 15 anos, de uma maneira informal até entrar na graduação". O professor nos traz que essa inserção prematura no ensino de música se deve muitas vezes pelo contexto socioeconômico e sociocultural:

Pela minha história socioeconômica, cultural, eu moro sozinho desde muito cedo, eu pago as minhas contas. Eu não via, não existia a possibilidade de ficar desempregado. Existia até ficar desempregado, mas sem trabalho, não. No campo da música, o ensino sempre foi o lugar que me permitia segurança, eu não posso negar que isso foi fundamental, antes de entrar no curso para escolher ensinar. A segurança profissional, a segurança financeira, a possibilidade de não ficar dependendo de cachê, isso contou de forma fundamental na escolha do curso. Isso foi, no primeiro momento, o que me levou e foi fundamental. (L.S., 2019). 
No caminho descrito até aqui, o professor F.A., que possui mais de trinta anos de atuação na docência em diferentes países, tais como Argentina, Rússia e Portugal, descreve algo sobremodo semelhante.

Eu comecei a me dedicar fundamentalmente ao ensino da música quando eu vim para cá [Portugal]. Não era o objetivo principal, mas foi esta questão, e sempre foi o meio que os músicos têm para sobreviver, já te expliquei o porquê. Infelizmente as escolas de música são um lugar onde o músico vai encontrar um ordenado para ter uma estabilidade econômica mínima. (F.A., 2019).

O alcance permitido por meio da revisitação do passado admite para muitos destes docentes uma compreensão alargada de sua trajetória, de tomada de consciência:

Você sabe que a gente vem de uma realidade de vida que não temos escolha, você é levado fazer aquilo. É como a fome, quando você percebe você entrou no mercado e roubou para comer. Nunca imaginaria que seria professor. Quando você é jovem você fica com aqueles pensamentos mirabolantes: "vou tocar e vou ganhar muito dinheiro..." e aí quando você começa a ter mais consciência das coisas você percebe que está dando aula para um aluno, depois um outro. Você vai na escola de alguém e dá uma outra aula e as coisas começam a acontecer (F.S., 2019).

Por isso, Josso (2007) nos mostra, de forma contundente, que a tomada de consciência é concebida em um processo permanente de identificação ou diferenciação. Ela nos induz a um movimento de contemplação para os sinais socioculturais que tingem a nossa existencialidade:

Às constatações que questionam a representação convencional de uma identidade, que se poderia definir num dado momento graças à sua estabilidade conquistada, e que se desconstruiria pelo jogo dos deslocamentos sociais, pela evolução dos valores de referência e das referências socioculturais, junta-se a tomada de consciência de que a questão da identidade deve ser concebida como processo permanente de identificação ou de diferenciação, de definição de si mesmo, através da nossa identidade evolutiva, um dos sinais emergentes de fatores socioculturais visíveis da existencialidade. É por essa razão que essas identidades num constante vir-a-ser, manifestação de nossas existencialidades em movimento, são em certos períodos históricos mais fortemente atingidas pelos efeitos desestruturadores de mudanças sociais, econômicas e/ou políticas. (JOSSO, 2007, p. 415).

\section{Na busca de si, o sentido de si no e com o outro}

Os sujeitos sociais aqui mencionados constroem um mundo particular que, por vezes, parece onírico. Neste mundo se entrecruzam experiências ímpares, alteridade e uma perspectiva pelo futuro amiúde abalizada pelo passado.

Esse percurso permite a construção de um conjunto de valores que se resguarda 
frequentemente no olhar para o outro, no ser com o outro, no dar-se ao outro, construindo-se na alteridade, como verificamos na fala do professor I.F.:

Daí eu penso: no que a música me contribuiu? Em saber que eu tenho que dar tudo que eu tenho. Se eu tenho que dar duzentos por cento, eu vou dar duzentos por cento. Isto foi o que a música, a parte como músico me entregou na docência: quando entrar num projeto, entrar de cabeça e vamos em frente. Foi uma escapatória que a música me deu quando era pequenino. Quando ia tocar, eu sabia que tinha que dar cem por cento, duzentos por cento para contribuir para todo o grupo, então essa foi a parte que o músico me deu para enquanto professor. Aprendi a não desistir de ninguém, que todos têm uma hipótese e que eles podem escolher, que é a parte mais importante. (I.F., 2019).

O discurso de I.F., um professor que atende centenas de alunos por meio de um dos maiores projetos sociais de Portugal, se espelha na fala do professor F.S., que, por sua vez, atua no ensino particular de instrumento musical em uma das maiores metrópoles brasileiras.

Sabe quando você se torna professor? Quando você percebe o outro, porque, até você ter contato com o outro, fica tudo em um mundo de ideias, num limbo. As coisas que você aprendeu na vida, você até usa mais. E o que você aprendeu na academia, o que você faz com aquilo, como que você utiliza? Mas, quando você tem contato com o outro, você mistura os dois e vê como de fato é ensinar. (F.S., 2019).

Essa percepção do outro, essa interação com o outro é indissociável do reconhecimento de si declarado por Ricoeur (2006). O filósofo diz que, para que haja o reconhecimento de si, é necessário um "lugar" para além da alteridade, nos lembrando que esse caminho envolverá o amor-próprio, a humildade e aprender acerca de si mesmo. Pois como eu posso amar e reconhecer o outro se eu não me reconheço? (RICOEUR, 2006).

Esse percurso do reconhecimento do momento de se "tornar professor" é delicadamente delineado por um conjunto particular de vivências, nas quais se reconhece o sentido da sua ação no mundo como músico e como professor, a partir do outro coletivo, pelas memórias ancestrais que a música transporta.

Primeiro eu comecei a dar aula de música e depois aula de capoeira. Hoje eu acredito que o que mais me trouxe para ser professor foi a experiência com a capoeira. Porque a capoeira não é só corpo, ela tem muita musicalidade. Tem toda uma relação histórica, corpo e cantiga, ancestralidade. A todo momento há um envolvimento, uma música diferente. Cada ritmo tem uma proporção, tem uma intencionalidade. Isso me fez buscar mais, buscar esse professor que transmite uma ideia... A partir daí a música começou a fluir, dando aula de percussão como foco nos ritmos de matriz africana da nação Angola. (D.X., 2019).

O professor D.X., que atua com pessoas em situação de rua em uma das capitais mais populosas do Brasil, segue esclarecendo que esses aspectos relacionados acabam se tornando um diferencial no exercício da docência. 
Esse lance de trabalhar a música da nação Angola me impulsionou muito a dar continuidade no trabalho de professor. E eu sou de nação Angola, do candomblé de nação Angola, tenho a experiência com a docência e tenho a experiência como músico. Isso porque dentro da música existem diversas pessoas que ensinam música popular, ensinam os ritmos da nação Ketu, mas da nação Angola eu busquei, pesquisei e não encontrei outra pessoa que trabalhasse isso. (D.X., 2019).

A docência é por vezes descrita como um acontecimento desprovido de projeto pessoal inicial, mas a casualidade não impede o encontro para outros valores, tais como engajamento e positividade, que se consubstanciam, mais uma vez, na descoberta de um sentido, um sentido de si e da sua escolha profissional na relação com o outro e com a sua transformação, como se manifesta o docente F.S.:

Pelo menos para mim não existia o desejo de ser professor. Mas hoje eu penso que tudo isso - o conhecimento, as minhas vivências - influencia o meu prazer em ser professor. Quando eu penso na transformação que a ação de um professor pode provocar e [que] essas ações podem ser positivas, vem para mim a certeza de que a minha escolha pela docência foi mais do que acertada. (F.S., 2019).

Este encontro despretensioso com o ensino acontece por vezes sem qualquer retorno financeiro, como nos conta o professor D.X.:

Eu acho que foi uma consequência. Eu não imaginava que eu daria aula, porém eu tive professores muito bons, como pessoas também. Eu reunia os colegas e estava ali estudando, eu passando algumas coisas, e assim eu fui me encantando. Até porque algumas pessoas me perguntam: "Ah, você está nessa porque dá dinheiro...". Eu passei oito anos ensinando sem ganhar nada, como voluntário. Eu tinha o prazer de estar ali ministrando as oficinas. Foi acontecendo e rolou. (D.X., 2019).

Desta maneira, muitos músicos "percebem" o enlace com o ensino e com o universo da música posteriormente, com o regresso ao imagético da infância, do percurso sociocultural e socioeconômico percorrido.

Eu nasci no Calabar ${ }^{6}$ e fui criado entre o Calabar e o Alto das Pombas, comunidades de Salvador onde tem uma efervescência cultural muito forte. Eu cresci vendo os grupos de samba duro, os grupos de pagode, os grupos de samba. $\mathrm{O}$ meu tio colocava, meu pai teve uma banda também, embora não seja músico, então eu fui criado dentro deste contexto da música. No primeiro momento não vislumbrava que isso fosse algo que iria virar profissão, mas sem dúvida aquilo ali já estava influenciando o caminho que viria posteriormente, a música e a sala de aula. (L.S., 2019).

O encontro com estas dimensões se torna possível com o narrar-se. De acordo

6 Calabar é uma das comunidades mais carentes da capital baiana. Composta por população de baixa renda, possui a $1^{\text {a }}$ Base Comunitária de Segurança inspirada nas Unidades de polícia pacificadora - UPP's do Rio de Janeiro, no Brasil. 
com Marie-Christine Josso (2007), é possível compreender elementos formativos e de aprendizagem por meio da abordagem biográfica, trazendo no bojo elementos subjacentes de identidade.

Ainda que a abordagem biográfica desenvolvida em situações educativas não tenha como prioridade a construção da identidade, as modalidades e objetivos de nossas pesquisas, baseadas no trabalho biográfico (construção da história escrita, co-análise e co-interpretação em situação de grupo), essa abordagem centrada na compreensão dos processos de formação, de conhecimento e de aprendizagem, enfoca, de certa forma, a questão da identidade. (JOSSO, 2007, p.419).

Por isso, Josso (2007) nos mostra, de forma contundente, que a tomada de consciência é concebida em um processo permanente de identificação ou diferenciação. Ela nos induz a um movimento de contemplação para os sinais socioculturais que tingem a nossa existencialidade.

Às constatações que questionam a representação convencional de uma identidade, que se poderia definir num dado momento graças à sua estabilidade conquistada, e que se desconstruiria pelo jogo dos deslocamentos sociais, pela evolução dos valores de referência e das referências socioculturais, junta-se a tomada de consciência de que a questão da identidade deve ser concebida como processo permanente de identificação ou de diferenciação, de definição de si mesmo, através da nossa identidade evolutiva, um dos sinais emergentes de fatores socioculturais visíveis da existencialidade. É por essa razão que essas identidades num constante vir-a-ser, manifestação de nossas existencialidades em movimento, são em certos períodos históricos mais fortemente atingidas pelos efeitos desestruturadores de mudanças sociais, econômicas e/ou políticas. (JOSSO, 2007, p.415).

A partir dessas narrativas, verificamos as sobreposições de períodos e vivências históricas. O músico português F.A. descreve que a sua constituição como docente é uma "mistura de experiências culturais", de encontro com outros coletivos, nas quais se vai construindo a sua identidade:

Mas o que me influencia e me influenciou a ser de fato este professor foi mistura das experiências culturais, pois tu vais colhendo. Entre a minha cidade natal e Buenos Aires já existe uma diferença, e depois de Buenos Aires para Moscou... isto foi mortal, uma sacudidela bastante grande. Uma riqueza humana que, claro, influencia, mas eu não sei dizer como. Isto faz de ti uma pessoa diferente e muitas vezes com os teus alunos. Se tu me perguntares "és argentino?", te responderei: "sim, sou argentino". Mas isto, agora passei mais tempo fora da Argentina do que vivi lá, entende? Depois há coisas que faço porque sou português, há coisas que ficaram em mim que são da Rússia e que parte de mim sentem em russo, e há coisas que ficaram em mim que são da minha primeira juventude, as quais são do sítio ${ }^{7}$ onde eu nasci. Isto faz deste docente uma espécie de saco, onde vão caindo coisas, hábitos culturais, línguas e outros saberes. (F.A., 2019).

7 Termo utilizado em Portugal que equivale a um local, um ponto determinado ou uma zona. 
Este encontro consigo, com o seu "próprio" perfil docente, é ponto nevrálgico nesta construção do sentido de si como docente. Isso porque se entrelaçam experiências, saberes, vivências e, de forma contundente, o autoconhecimento, como nos declara F.S.

Muitas vezes estamos tão apegados aos nossos métodos que você toca junto ao aluno, mas não consegue escutar a sua voz naquela construção. É um solo seu, você toca junto, mas não percebe o outro. Por isso estes saberes que adquiri fora da academia acabaram por me levar a trabalhar com cada aluno de forma diferenciada. Você lembra do nosso professor? Ele trabalha o repertório que cada um de nós relacionava melhor, ele buscava valorizar o que cada um de nós tinha de melhor, entendia o contexto de cada um de nós, lembra? Estes saberes, eu não encontrei na universidade, mas nesta época do ensino médio. A vivência de rua e destes outros saberes é que me faz o professor que eu sou hoje. (F.S., 2019).

\section{A minha experiência de vida e como músico interfere diretamente na minha relação com o outro, como professor}

Nesta consciência acerca do conjunto de saberes docentes adquiridos ao longo do percurso formativo, um professor brasileiro destaca um ponto como diferencial, quando enuncia que a prática musical dos palcos contribuiu para o formato de aula que utiliza.

A formação como músico é muito importante porque você começa a entender o
que cada pessoa pensa ou o que cada pessoa quer com a sua aula, qual é o ob-
jetivo. O estilo de música que a pessoa toca, como ela toca, o tipo de ambiente.
Então você já começa a identificar e começa a pontuar para as pessoas na sala
sobre o uso do microfone, sobre a forma de estar no palco, sobre como tocar,
como deve ser a pegada. Você ensina como tocar no instrumento para que o
som saia dessa ou daquela forma. Se for tocar no teatro, deve ser nessa ou na-
quela dinâmica... Eu acredito que essa experiência dos palcos contribui até hoje
em minhas aulas, de como vai acontecer ou se você vai tocar com tal artista,
porque você já tocou com ele, é bom fazer dessa ou daquela forma. (D.X., 2019).

Como nos lembra Tardif (2002, p.11), “O saber deles está relacionado com a pessoa e a identidade deles, com a sua experiência de vida e com a sua história profissional, com as suas relações com os alunos em sala de aula". Tal como ilustrado por Cavaco (2009, p.225), "O estudo da experiência e dos adquiridos experienciais não se pode circunscrever à descrição do percurso realizado, tornando-se essencial aceder à interpretação do vivido por parte do sujeito implicado na ação". Essa percepção do lugar que o saber experiencial ocupa dentro destas práticas pedagógicas se dá pela interpretação do próprio professor, como aquele que não só reflete, mas interpreta a sua narrativa.

Esse mosaico de diferentes saberes e fazeres perpetram os loti ímpares de cada um dos professores aqui entrevistados. Ao se reconhecer como "professor de música", se reconhece também como "possuidor" desta ou daquela maneira de ensinar, dentro de diferentes maneiras de ser e ensinar música. O professor D.X., que atuou em diversos projetos sociais, descreve de que maneira ele situa os saberes utilizados em suas aulas de música: 
O que eu faço, o que eu passo, o que eu tento ministrar vem destes saberes empíricos, do popular, da religiosidade, da musicalidade afro-brasileira, indígena. Muito pouco disso vem da academia. Eu acredito que esses saberes fazem hoje $90 \%$ do que eu ministro como professor. Eu sinceramente não consigo identificar em minhas aulas muito do que eu vivi e aprendi na academia, na minha realidade de professor. (D.X., 2019).

Semelhantemente, outro professor nos mostra que compreende que a sua experiência profissional está associada à sua trajetória de vida e, nesta, a relação com o outro.

Eu acho que minha formação como professor é minha experiência de vida, vou para a sala com tudo que eu já vivi. Eu comecei a notar que muito do que eu sou como professor eu aprendi com minhas colegas, pedagogas de 25 anos de sala de aula, 30 anos de sala de aula, colegas músicos. Quando eu tive contato com o trabalho de Tardif sobre saberes docentes, experienciais, disciplinares, acadêmicos e profissionais, eu comecei: "poxa, é por aqui". Eu acho que tem muito a ver com o que ele está falando com o que foi minha vida, com o que foi a minha formação e aí eu já comecei a trabalhar com meus alunos a partir desta perspectiva, o próprio $\operatorname{Tardif}^{8}$ quando fala da ação reflexiva. (L.S., 2019).

Nota-se que, nesse processo de narrar-se, é oportunizada a percepção para delicadezas presentes no percurso da formação docente, mesmo quando emergem de forma inconsciente. Este conjunto de elementos é percebido e aclarado também por Maurice Tardif (2002, p.213):

O professor possui competências, regras, recursos que são incorporados ao seu trabalho, mas sem que ele tenha, necessariamente, consciência explícita disso. Nesse sentido, o saber-fazer do professor parece ser mais amplo que o seu conhecimento discursivo.

O estudo permite ainda abalizar que estas trajetórias descritas pelos entrevistados delineiam, a posteriori, uma descoberta, um encontro com o âmbito educacional de atuação. $O$ docente português I.F. nos traz que o seu lugar de atuação lhe permite fazer a diferença como professor, encontrando na transformação social o seu sentido.

Eu já tinha ideia de me formar na parte pedagógica, sempre me fascinou e foi algo que sempre me identifiquei, em estar com as crianças, poder brincar e ao mesmo tempo poder aprender alguma coisa. Depois que conheci e passei a ver aquela realidade, eu consegui ver que consigo fazer diferença mais enquanto sou professor. Consigo dar ferramentas aos alunos, consigo melhorar, consigo melhorar mais a sociedade, enquanto na academia não tinha tanto isso. Lá era: "É isso, tens que seguir esse caminho". Não dá para mudar a maneira de pensar, já estão padronizadas, e aqui no projeto social é mais fácil. (I.F., 2019).

8 Professor pesquisador canadense. Para o autor, a docência é uma profissão de interações humanas. 
Este sentido, esta crença de que existe um papel importante da docência na promoção social é partilhada entre os professores. Para alguns deles, a profissão de professor está imbuída dessa transformação por meio da música, e isto é entendido como um ato sublime.

Eu tenho a convicção de que o ato de educar, o ato de promover uma educação através da música é um ato muito sublime, não pela ação do professor, mas pelo que a educação provoca. Não é pelo professor, o professor é apenas um veículo de promoção da transformação. Então hoje eu tenho certeza que sim. (F.S., 2019).

Neste retorno ao momento da "descoberta" da profissão de professor de música, brota também de forma indissociável nas falas dos entrevistados o lugar primoroso da experiência, como demonstra um professor que atua no ensino regular brasileiro.

\begin{abstract}
A minha experiência de vida interfere diretamente na minha relação com o outro, me levando a uma postura mais humana. Como eu sou morador de um bairro periférico, onde eu sei o quanto a carência das relações humanas interfere muitas vezes até no desenvolvimento de uma criança, o quanto a ação pública interfere, o quanto a falta de um alimento interfere no desenvolvimento, de que forma as ações desumanas interferem ao você perceber que a violência mexe totalmente na dinâmica de uma localidade. Eu começo a perceber que essa minha vivência, essa minha percepção, essa minha convivência com pessoas em contexto social semelhante ao meu me levam a analisar os outros espaços que eu tenho acesso. Noto que existem pessoas que não têm relação nenhuma com estas questões que eu citei acima. Eu consigo colocar na balança estas diferentes realidades, vendo o quanto a minha ação como professor pode fazer a diferença dentro destes espaços. (V. S., 2019).
\end{abstract}

Esta fala do professor V.S. nos coloca em xeque-mate para a questão da humanidade necessária à atuação como professor, uma profissão de relação. Arroyo (2013) defende que, por mais que se ensaie, não há como fugir da dimensão docente e que estaremos sempre diante da "humana docência".

Também o professor L.S. - que descreveu anteriormente sua vivência em uma das comunidades mais pobres da cidade de Salvador, no Brasil - esclarece que construiu para si uma representação de professor de música imbuído de formar para além do instrumento musical.

Eu dizia que queria ser professor dessa área de educação musical. Eu até poderia dar aula de instrumento, mas... não era o meu foco. Eu não queria ser um cara que vai só formar instrumentista, queria formar professores de música, pessoas, que na minha perspectiva podem ser agentes de transformação social. Era muito nessa linha porque eu me via nesse lugar, pensava nesses contextos, então eu acho que foi assim que foi construído a figura do professor para mim. (L.S., 2019).

Ele segue nos contando acerca de um processo dilatado de atuação no ensino de música com vistas à construção de sua carreira como professor: 
Eu quero ser um professor que dê aula, fale dessas coisas e que tenha vivido essas coisas. Então a partir daí eu comecei a trabalhar em todos os contextos que a vida me ofertava, eu trabalhei com musicalização infantil, eu trabalhei com adulto, trabalhei na escola básica, fiz projeto social, fiz trabalho voluntário, dei aula de instrumento particular, dei aula de música, dei aula tanto na rede particular quanto na rede pública municipal, federal, o que me chamavam. Tem um coral aqui que é só para ensaiar para fazer apresentação. Eu não acreditava naquilo, mas eu ia para saber como é que era, então acho que foi se construindo a minha formação. (L.S., 2019).

Esta dimensão que ultrapassa as questões sonoras alcança temáticas transversais à vida humana, ao cotidiano, à humanidade, como nos traz o professor F.S.

Quando você percebe toda a família de um aluno envolvida no processo, onde eles te agradecem e você percebe que o seu trabalho influencia na vida do outro de uma forma positiva... é gratificante. Quando um aluno seu vem conversar com as coisas que não têm nada a ver com música, você entende que seu trabalho é com seres humanos, você descobre então que os temas são transversais. São coisas que realmente importam para estas pessoas, cara, são adultos, mães de filhos que você percebe que a aula não é aula de música, é uma terapia mesmo. (F.S., 2019).

Por vezes, é possível interpretar na linha da escrita destas narrativas uma identidade que está em permanente construção, onde os alicerces se anteparam na escuta, na percepção e no acolhimento do outro. É o "eu professor" que se edifica por causa do "outro", nos levando a lembrar a indissociabilidade do nosso existir.

\section{As cores do quadro que se pintou}

Deste estudo emergiram histórias de vida e se entrecruzaram marcadas experiências, em diferentes contextos educacionais. As cores deste quadro final remetem à alteridade, ao exemplo, aos saberes, à experiência... O reconhecimento tão ensejado nestas linhas se aprofunda em outros termos, tais como devolver, doar, amar. Mas uma pesquisa acadêmica permite-se tecer acerca do amor? O psicanalista Jacques Lacan (2005) nos ajuda nesta busca ingerível por respostas concretas e racionais.

Muitas das razões alegadas para as opções e sentimentos em relação ao tornar-se professor, na verdade, parecem apontar para algo que vai além da explicação racional. Ou seja, embora justificativas sejam dadas para essa ou aquela escolha, algumas delas parecem ser irredutíveis e, em última análise, incompreensíveis até mesmo para aquele que a fala. (LACAN, 2005, p.190).

Aqui, retomamos Paul Ricoeur (2006, p.114), quando nos lembra que,

Sob a forma reflexiva do narrar-se, a identidade pessoal se projeta como identidade narrativa. Estes professores projetam suas identidades, tecendo a partir da 
reflexão não só de si, mas como se situam no mundo e em suas salas de aula, na perspectiva do outro.

A gratidão leva a retribuir o reconhecimento que se recebe. Mas esse reconhecimento só acontece quando descubro o outro, o contemplo e devolvo este reconhecimento. Essa reciprocidade da alteridade, segundo o teórico, leva a um "estado de paz". A profundidade alcançada por Ricoeur soa de forma vibrante, pois no seu pacto teórico ele arrola o reconhecimento com valores tais como o amor, a alteridade e a mutualidade.

Os professores que aqui ofertaram suas histórias de vida permitiram não só a nossa reflexão acerca da identidade que está abrigada na narrativa, mas nos admitiram avançar no nosso autorreconhecimento, pois nós formamos também ao refletir sobre outros diferentes percursos de formação docente, como nos lembram Nóvoa e Finger (1988, p.116): "A formação é inevitavelmente um trabalho de reflexão sobre os percursos de vida". O mergulho em cada uma dessas falas nos permite achar sentido sobre as diferentes formas de ser e estar na educação, pois a "educação é assim feita de momentos que só adquirem o seu sentido na história de uma vida" (DOMINICÉ, 1988, p.140).

Aqui, neste lugar de falas atemporais, cruzamos com renomados músicos em seus países de origem, doutores em música com produção acadêmica reverenciada, professores que estão na ponta de políticas públicas que versam sobre pobreza e desigualdade social, mas também conseguimos alcançar por meio das narrativas que muitos desses destacados "professores de música" iniciaram seus trabalhos sem diploma, alguns ainda na transição da adolescência para a juventude.

Por isso, esta pesquisa lança luz não apenas sobre trajetórias inusitadas, mas nos ajuda a compreender sobre tempos vindouros, permitindo o alcance de uma identidade que é dinâmica e não estática, em que a história de vida do professor constrói a sua identidade.

A pessoa, compreendida como personagem de narrativa, não é uma entidade distinta de suas "experiências". Bem ao contrário: ela divide o regime da própria identidade dinâmica com a história relatada. A narrativa constrói a identidade do personagem, que podemos chamar sua identidade narrativa, construindo a da história relatada. É a identidade da história que faz a identidade da personagem. (RICOEUR, 1991, p.176).

Mas como podemos responder à pergunta desta pesquisa? De que maneira se dá o "percurso do reconhecimento" deste professor de música? O nosso norte teórico nos auxilia:

Quando é que perguntávamos, um indivíduo pode considerar-se reconhecido? A exigência do reconhecimento não pode se tornar indeterminável? Em vista dessa questão existencial, propusemos a hipótese de que, na troca de dons, os parceiros sociais experimentavam um reconhecimento efetivo. (RICOEUR, 2006, p.257). 
Aqui conhecemos a trajetória ímpar de cada um destes professores entrevistados e contemplamos o processo de troca de dons em seus trajetos formativos: ensinam a fazer fazendo, por meio do saber da experiência, inebriados pela dádiva e pela alteridade. Ricoeur (2006, p.255), ao beber na imortalizada frase do filósofo Marcel Mauss de Essai sur le don, nos constitui sobre a docência e a alteridade na conclusão deste estudo: "Nós nos damos ao dar, e se nos damos é porque nos devemos, nós e nosso bem, aos outros".

\section{Referências}

ABREU, Delmary Vasconcelos de. Compreender a profissionalização de professores de música: contribuições de abordagens biográficas. Opus, Porto Alegre, v. 17, n. 2, p. 141-162, dez. 2011.

ANDRÉ, Marli Eliza Dalmazo de. Perspectivas atuais da pesquisa sobre docência. In: BUENO, Belmira; CATANI, Denice Bárbara; SOUSA, Cynthia Pereira de et al. Docência, memória e gênero: estudos sobre formação. São Paulo: Escrituras, 1997. p. 65-74.

AMADO, João (coord.). Manual de Investigação Qualitativa em Educação. Coimbra: Imprensada Universidade, 2014.

ARROYO, Miguel. Ofício de Mestre. Imagens e autoimagens. 15. ed. Rio de Janeiro: Vozes, 2013.

BELLOCHIO, Cláudia. A formação profissional do educador musical: algumas apostas. Revista Abem, Porto Alegre, n. 8, p. 17-24, mar. 2003.

BRASIL, Anderson. Música e periferia: o sonho e o real em um mundo negro chamado Bahia. Curitiba: APPRIS, 2019.

BURNIER, Suzana et al. História de vida dos professores: o caso da educação profissional. Revista Brasileira de Educação, Rio de Janeiro, v. 12, n. 35, p. 343-358, maio/ago. 2007.

CAVACO, Carmen. Experiência e Formação experiencial: a especificidade dos adquiridos experienciais. Educação Unisinos, São Leopoldo, v. 13, n. 3, p. 220-227, 2009.

CHAGAS NETO, Antônio. Interações sociais construídas no ensino particular de violino e flauta doce: estudos de caso sobre relações de ensino e aprendizagem com crianças de dois e três anos. 2018. 163 f. Tese (Doutorado em Música) - Universidade Federal da Bahia, Salvador, 2018. 
CONNELLY, Michael; CLANDININ, Jean. Stories of experience and narrative inquiry. Educational Researcher, Washington, v. 19, n. 5, p. 2-14, jun./jul. 1990.

DOMINICÉ, Pierre. O que a vida lhes ensinou. In: NÓVOA, António; FINGER, Mathias (org.). O método (auto)biográfico e a formação. Lisboa: Ministério da Saúde, Departamento de Recursos Humanos da Saúde, Centro de Formação e Aperfeiçoamento Profissional, 1988. p. 131-153.

HARARI, R. Uma introdução aos quatro conceitos fundamentais de Lacan. Campinas: Papirus, 1990.

JOSSO, Marie-Christine. História de vida e projeto: a história de vida como projeto e as "histórias de vida" a serviço de projetos. Educação e Pesquisa, São Paulo, v. 25 n. 2, p. 11-23, jul./dez. 1999.

JOSSO, Marie-Christine. Transformação de si a partir da narração de histórias de vida. Educação, Porto Alegre, v. 30, n. 3, p. 413-438, set./dez. 2007.

JOSSO, Marie-Christine. Experiências de vida e formação. 2. ed. São Paulo: Paulus, 2010.

JOVCHELOVITCH, Sandra; BAUER, Martin. Entrevista narrativa. In: BAUER, Martin; GASKELL, George. Pesquisa qualitativa com texto, imagem e som: um manual prático. Petrópolis: Vozes, 2002. p. 90-113.

KRAEMER, Rudolf-Dieter. Dimensões e funções do conhecimento pedagógicomusical. Em Pauta, Porto Alegre, v. 11, n. 16/17, p. 49-73, abr./nov. 2000.

LACAN, Jaques. A angústia. O Seminário, livro 10. Rio de Janeiro: Jorge Zahar, 2005.

LATOUR, Bruno. Ciência em ação. Como seguir cientistas e engenheiros sociedade afora. Trad. Ivone Castilho Benedetti. São Paulo: Unesp, 2000.

NÓVOA, António (org.). Vidas de Professores. Porto: Porto Editora, 2000.

NÓVOA, António. Os professores e as Histórias da sua vida. In: NÓVOA. António (org.). Vidas de professores. Portugal: Porto Editora, 1992.

NÓVOA, António; FINGER, Mathias. O método (auto)biográfico e a formação. Lisboa: MS/DRHS/CFAP, 1988.

PASSEGGI, Maria da Conceição. A experiência em formação. Educação, Porto Alegre, v. 34, n. 2, p. 147-156, 2011. 
PASSEGGI, Maria da Conceição (org.). Tendências da Pesquisa (auto) biográfica. Natal: EDUFRN; São Paulo: Paulus, 2008.

RICOEUR, Paul. Memória, a história, o esquecimento. Campinas: Unicamp, 2007.

RICOEUR, Paul. O percurso do reconhecimento. São Paulo: Loyola, 2006.

RICOEUR, Paul. Da metafísica à moral. Rio Tinto: Piaget, 1997.

RICOEUR, Paul. O si-mesmo como um outro. Trad. Luci Moreira Cesar. Campinas:

Papirus, 1991.

SALDANHA, Fernando Acílio Maia. Do Sujeito capaz ao sujeito de direito: um percurso pela filosofia de Paul Ricoeur. 2009. 367 f. Tese (Doutoramento em Filosofia) Faculdade de Letras, Universidade de Coimbra, Coimbra, 2009.

TARDIF, Maurice. Saberes docentes e formação profissional. Petrópolis: Vozes, 2002.

\section{Entrevistas}

D.X. Entrevista concedida a Anderson Brasil em 26 set. 2019.

I.F. Entrevista concedida a Anderson Brasil em 1 dez. 2019.

F.A. Entrevista concedida a Anderson Brasil em 24 nov. 2019.

F.S. Entrevista concedida a Anderson Brasil em 28 set. 2019.

L.S. Entrevista concedida a Anderson Brasil em 29 set. 2019.

V.F. Entrevista concedida a Anderson Brasil em 27 nov. 2019.

V.S. Entrevista concedida a Anderson Brasil em 28 set. 2019. 